\title{
PERSONAL CHARACTERISTICS OF PATIENTS WITH DEPRESSIVE DISORDERS
}

\author{
Oleksandr Belov \\ Ph.D., Associate Professor, National Pirogov Memorial Medical University, Ukraine \\ e-mail: oleksbelov@gmail.com,orcid.org/0000-0002-0156-0777
}

\section{Summary}

The aim of this paper is to study the features of the personal characteristics of patients with depressive disorders at the present stage, taking into account gender and age factors. Clinically examined 107 men and 138 women with depressive disorders (ICD-10 codes F31.3, F31.4, F32.0, F32.1, F32.2, F33.0, F33.1, F33.2) using Mini-mult test. Persistent pathocharacterological changes were revealed in patients with depressive disorders, the basis of these transformations are persistent depressive manifestations in combination with a high level of anxiety, asthenia and hypochondriasis, as well as moderate manifestations of hysteria, psychopathy, paranoia and schizoidism. In men, more pronounced manifestations of depression, paranoia and schizoidism were revealed, and in women - psychasthenia, hypochondriasis and psychopathic manifestations. The manifestations of depression, hypochondriasis, psychopathy, paranoia and schizoidness, which are least pronounced in the young age group (up to 30 years old), and most pronounced in the older age group (45 years and older). The manifestations of psychasthenia are minimal in the younger age group, reach the highest level in the middle age group (30-44 years old), and slightly decrease in the older age group.

Keywords: depression, anxiety, hypochondriasis, hysteria, psychopathy, paranoia, psychasthenia, hypomania.

DOI https://doi.org/10.23856/4331

\section{Introduction}

Depressive disorders are one of the main problems of modern psychiatric science and practice (Fekadu et al., 2017; Ogbo et al., 2018; Kraus, 2019). Depressive disorders has been ranked as the third cause of the burden of disease worldwide by WHO, which has projected that this disease will rank first by 2030 (Malhi et al., 2018). Depressive disorders are associated with important risk for suicidal behavior, reduced of quality of life, and social maladaptation both in patients with depressions and in their microsocial environment (Zuckerman et al., 2018; Pshuk et al., 2018). Depressive disorders in modern stage are characterized by polymorphism of symptoms, difficulty of diagnosis and resistance to therapy (Wiles et al., 2018; Limandri, 2018; McLachlan, 2018). An important factor in the development of preventive measures for depressive disorders is the study of their pathomorphosis; a some of important issues of clinical pathomorphosis of depressive disorders remain insufficiently studied, and the data of existing studies are incomplete and contradictory (Cleare, 2015; Markova, 2017). We have described some trends in the current socio-demographic and clinical pathomorphosis of endogenous depressions (Belov, 2019). In this regard, it is important to study the personal characteristics of patients with depressive disorders: current evidence suggests that depression is linked to traits such as neuroticism and negative emotionality, extraversion and positive emotionality, and conscientiousness; moreover, personality characteristics appear to contribute to the onset 
and course of depression through a variety of pathways (Klein et al., 2011: 269). Therefore, the study of the personal characteristics of patients with depressive disorders is important for the development of treatment, rehabilitation and prevention programs for depression.

\section{The aim of the study}

The aim is to study the features of the personal characteristics of patients with depressive disorders at the present stage, taking into account gender and age factors.

\section{Materials and methods}

With the observance of the principles of biomedical ethics, we have clinically examined 107 men and 138 women who applied for medical care at Vinnitsa Regional Psycho-Neurological Hospital from 2015 to 2019. The nosological structure of the contingent was as follows: bipolar affective disorder, the current episode of depression (ICD-10 codes F31.3, F31.4); depressive episode (F32.0, F32.1, F32.2); recurrent depressive disorder (F33.0, F33.1, F33.2). The average age of the men was $34.2 \pm 11.1$ years, and 33.2 \pm 11.4 years for women $(\mathrm{p}=0.422)$, the average duration of depression was $5.7 \pm 5.8$ years for men, and $4.5 \pm 5.4$ years for women $(p=0.064) .3$ subgroups were allocated in group of men and women depending on the age of patients at the time of the study: up to 30 years ( 38 men and 51 women), from 33 to 44 years (46 men and 53 women), 45 years and older (23 men and 34 women). The study was conducted using Mini-mult test (Zaytsev, 1981). Statistical analysis of differences between groups was carried out using non-parametric Mann-Whitney test.

\section{Results}

The personal profile of patients with depressive disorders is characterized high rates of depression (D): $81.6 \pm 4.3$ T-points $(82.7 \pm 6.1$ T-points in men, $80.7 \pm 1.9$ T-points in women, $\mathrm{p}=0.006$ ). The quantitative value of the depression indicator exceeds 80 points, which corresponds to the pathological level, and in men the indicator is significantly higher than in women (figure 1). In the profile of patients with depression, psychasthenia (Pt) also occupies high positions: 79.1 \pm 9.6 T-points $(76.0 \pm 10.1$ T-points in men, 81.4 \pm 8.7 T-points in women, $\mathrm{p}=0.035)$. Psychasthenia is also characterized by high scores (almost 80 points), but women have significantly higher scores than men. Another indicator in patients with depression exceeds the norm (more than 70 T-points): hypochondriasis (Hs) - 70.1 \pm 7.9 T-points $(67.2 \pm 9.1 \mathrm{~T}$-points in men, $72.2 \pm 6.1$ T-points in women, $p=0.025)$; this figure is also higher in women. Indicators on the rest of the clinical scales are within the normal range (less than 70 T-points): hysteria (Hy): $64.6 \pm 8.3$ T-points $(66.0 \pm 10.1$ T-points in men, 63.6 in women \pm 6.7 T-points, $p=0.060)$; psychopathic deviate $(\mathrm{Pd}): 64.4 \pm 11.9$ T-points $(63.6 \pm 11.2 \mathrm{~T}$-points in men, 65.0 $\pm 12.5 \mathrm{~T}$-points in women, $\mathrm{p}=0.761)$; paranoia $(\mathrm{Pa})$ : $64.4 \pm 7.4 \mathrm{~T}$-points $(67.2 \pm 8.3 \mathrm{~T}$-points in men, $62.4 \pm 6.0 \mathrm{~T}$-points in women, $\mathrm{p}=0.001)$; schizophrenia $(\mathrm{Sc})$ : $66.1 \pm 8.2 \mathrm{~T}$-points $(64.7 \pm 8.4 \mathrm{~T}$-points in men, $67.2 \pm 7.9 \mathrm{~T}$-points in women, $\mathrm{p}=0.057)$; hypomania $(\mathrm{Ma}): 45.1 \pm 10.2 \mathrm{~T}$-points $(44.0 \pm 12.4 \mathrm{~T}$-points in men, 45.9 \pm 8.2 T-points in women, $\mathrm{p}=0.416$ ).

The profile of patients in the middle age group (30-44 years) is also characterized by pathological (more than 80 T-points) depression levels: $82.7 \pm 3.1$ T-points $(84.4 \pm 3.4$ T-points in men, $81.2 \pm 1.8$ T-points in women, $\mathrm{p}=0.001$ ), but in this age group, the psychasthenia indicator exceeds the depression indicator: $83.4 \pm 9.3$ T-points $(81.2 \pm 9.5$ T-points in men, 


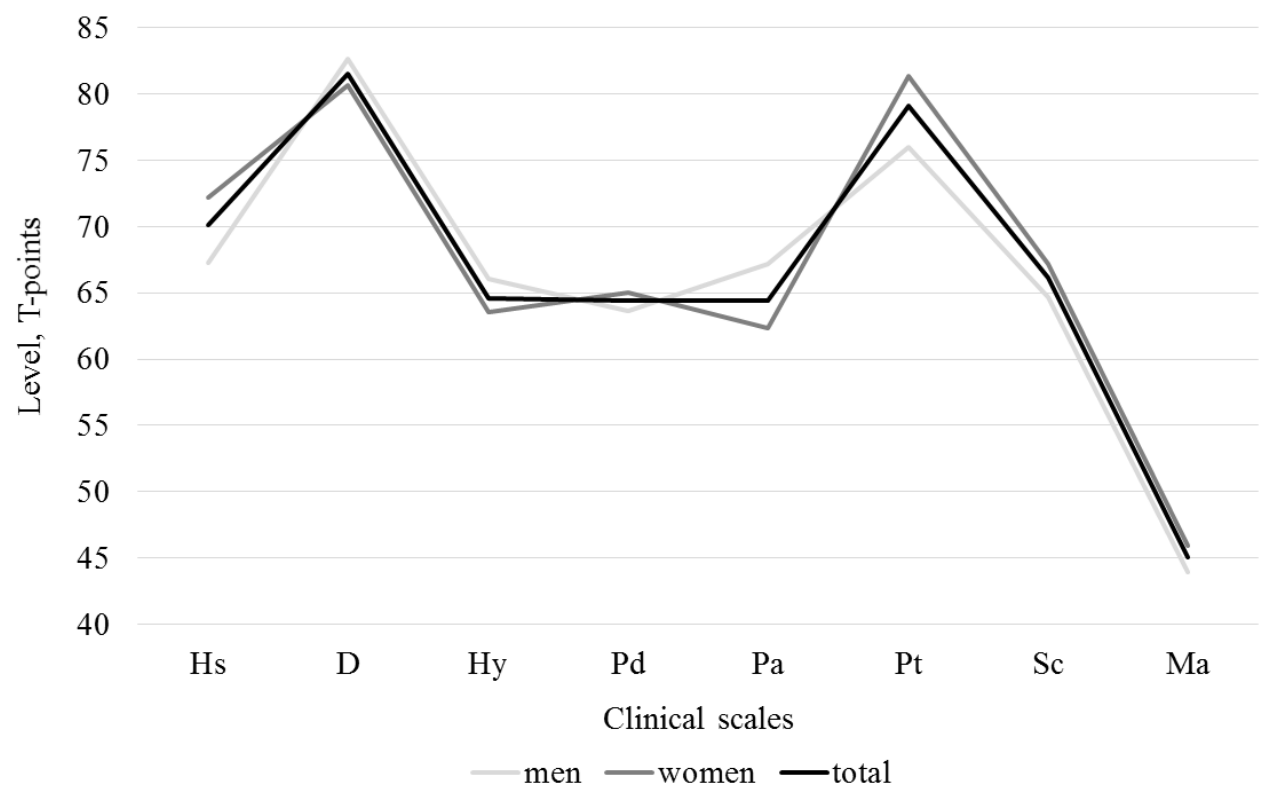

Figure 1. Personal profile of patients with depression in the age group up to 30 years

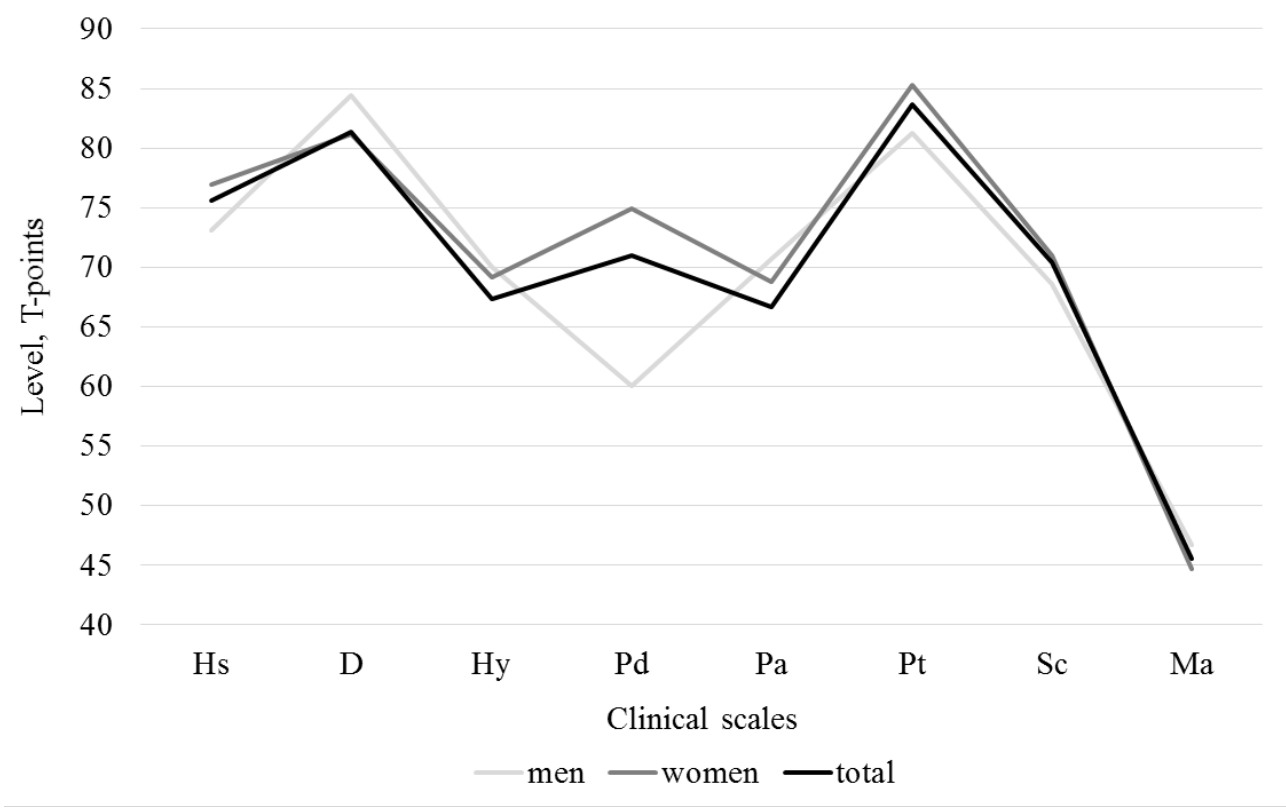

Figure 2. Personal profile of patients with depression in the age group from 33 to 44 years 
$85.3 \pm 8.8$ T-points in women, $\mathrm{p}=0.042$ ) (figure 2 ). The middle age group is also characterized by a higher indicator of hypochondriasis: $75.1 \pm 6.7$ T-points (73.0 \pm 8.1 T-points in men, $77.0 \pm 4.6$ T-points in women, $\mathrm{p}=0.018)$. Indicators on the rest of the scales are higher than in the younger age group, and approach the border of the norm (70 T-points), with the exception of hypomania: hysteria: $69.5 \pm 6.4$ T-points (70.0 \pm 7.7 T-points in men, 69.2 \pm 4.9 T-points in women, $\mathrm{p}=0.628)$; psychopathic deviate: $68.0 \pm 13.2 \mathrm{~T}$-points $(60.0 \pm 8.9 \mathrm{~T}$-points in men, 74.9 \pm 12.5 T-points in women, $\mathrm{p}=0.001)$; paranoia: $69.7 \pm 8.1 \mathrm{~T}$-points $(70.7 \pm 9.2 \mathrm{~T}$-points in men, 68.7 \pm 6.8 T-points in women, $\mathrm{p}=0.115)$; schizophrenia: $69.8 \pm 7.9 \mathrm{~T}$-points $(68.5 \pm 7.5 \mathrm{~T}$-points in men, 71.0 \pm 8.1 T-points in women, $\mathrm{p}=0.012)$; and hypomania: $45.6 \pm 8.8$ T-points (46.7 \pm 10.3 T-points in men, 44.7 \pm 7.2 T-points in women, $\mathrm{p}=0.172$ ).

In patients of the older age group, the indicators of depression reach the highest value among all groups: $83.8 \pm 2.9$ T-points $(85.7 \pm 3.4$ T-points in men, $82.5 \pm 1.6$ T-points in women, $\mathrm{p}=0.001)$, and psychasthenia indices slightly decrease in comparison with the average age group: 82.1 \pm 7.1 T-points (78.4 \pm 7.1 T-points in men, 84.6 \pm 6.1 T-points in women, $\mathrm{p}=0.002$ ) (figure 3). In this age group, the indicators of hypochondriasis reach the maximum: $77.2 \pm 4.9$ T-points (in men 75.0 \pm 5.2 T-points, in women 78.6 \pm 4.1 T-points, $\mathrm{p}=0.004$ ); hysteria: $69.4 \pm 4.5$ T-points (68.7 \pm 5.3 T-points in men, 69.9 \pm 3.8 T-points in women, $\mathrm{p}=0.283)$; psychopathic deviate: $69.2 \pm 11.7$ T-points $(62.7 \pm 9.8$ T-points in men, $73.6 \pm 11.0$ T-points in women, $\mathrm{p}=0.001)$; paranoia: 69.9 \pm 7.9 T-points (69.9 \pm 9.5 T-points in men, 69.8 \pm 6.7 T-points in women, $\mathrm{p}=0.606)$; schizophrenia: $69.8 \pm 8.7$ T-points $(63.3 \pm 7.5$ T-points in men, $74.2 \pm 6.4$ T-points in women, $\mathrm{p}=0.001)$ and hypomania: 48.0 \pm 9.9 T-points $(50.4 \pm 10.3$ T-points in men, 46.4 \pm 9.5 T-points in women, $\mathrm{p}=0.122$ ).

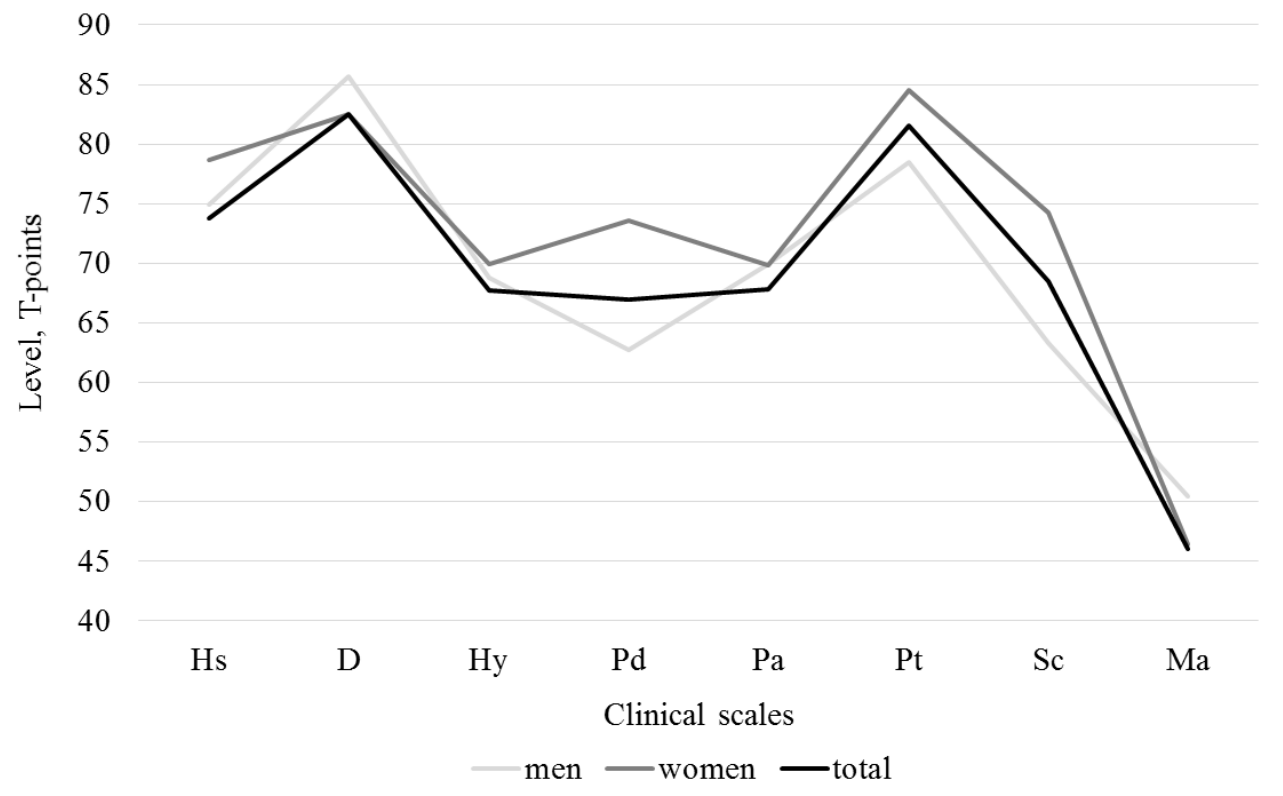

Figure 3. Personal profile of patients with depression in the age group 45 years and older

Statistically significant differences between different age groups were found for men between the younger and middle groups for hypochondriasis $(\mathrm{p}<0.01)$, psychasthenia $(\mathrm{p}<0.05)$, 
schizophrenia $(\mathrm{p}<0.05)$, between the younger and older age groups for hypochondriasis $(p<0.01)$, between middle and older age groups for schizophrenia $(p<0.05)$. For women, statistically significant differences were found between the younger and middle age groups for hypochondriasis $(\mathrm{p}<0.01)$, hysteria $(\mathrm{p}<0.01)$, psychopathic deviate $(\mathrm{p}<0.01)$, paranoia $(\mathrm{p}<0.01)$, psychasthenia $(\mathrm{p}<0.05)$ and schizophrenia $(\mathrm{p}<0.01)$. Significant differences between the younger and older age groups were found for hypochondriasis $(p<0.01)$, depression $(p<0.01)$, hysteria $(\mathrm{p}<0.01)$, psychopathic deviate $(\mathrm{p}<0.01)$, paranoia $(\mathrm{p}<0.01)$, psychasthenia $(\mathrm{p}<0.01)$ and schizophrenia $(p<0.01)$. Differences between the middle and older age groups were found for hypochondriasis $(\mathrm{p}<0.05)$ and depression $(\mathrm{p}<0.01)$.

\section{Discussion}

The personality profiles of patients with depression reflect both premorbid personality traits and pathocharacterological transformations caused by the prolonged course of depression. A depression score of more than 80 points corresponds to the severity of depression in the examined patients. The combination of high indicators on the scales of depression and asthenia reflects a high level of anxiety, sensitivity, self-doubt, frustration, difficulties in social adaptation and low self-esteem, which in patients with depression takes on the character of painful ideas of self-blame and self-deprecation. High rates of hypochondriasis are a correlate of somatic anxiety, and in depressed patients, they can also reflect the many unpleasant somatic sensations that accompany depression. Over time, such somatic fixations can acquire the properties of pathocharacterological personality traits. Patients with depression also showed high rates of hysteria, psychopathic deviate, paranoia, and schizophrenia. High rates of hysteria in patients with depression can be interpreted as withdrawal into illness, the desire to draw attention to their suffering, lack of vision of the future, loss of the ability to orderly activity, momentary reactions determined by the current situation. Increased rates of psychopathic deviate can be an indicator of social maladjustment, emotional instability, feelings of guilt, and often accompany the development of depression. The manifestations of paranoia in patients with depressive disorders reflect the rigidity of affect, fixation on negative emotions, the stability of low mood, and a feeling of insufficient support from others. High values on the scale of schizophrenia in depression reflect difficulties in interpersonal interaction, inability to understand the emotional state of others, ambivalence in relationships with the expectation of attention and support, and fear of coldness on their part. Low rates of hypomania naturally accompany the development of depression and correlate inversely with the severity of depressive phenomena. In general, individual patient profiles are highly variable and can be very different from one another.

The features of the age-related dynamics of personality changes in patients with depression reflect the progression of the depressive process and the formation of pathocharacterological personality changes associated with the long-term course of depression. The increase in persistent depressive manifestations with age is a natural reflection of the chronic nature of affective disorders; it is important to note that significant differences in the severity of stable depressive characteristics were found only in women, and these differences are most pronounced between the middle and older age groups. This corresponds to the tendency a more significant increase in the manifestations of depression at an older age, revealed in our studies towards (Belov, Pshuk, 2020). Psychasthenia is most pronounced in the middle age group, which is also consistent with our research data on the maximum values of personal anxiety in the middle age group with a further decrease in the older group (Belov, Pshuk, 2020). The reason for such features may be age-related changes, in particular, age-related mental rigidity and a decrease in 
mental reactivity with age. The natural increase in the manifestations of hypochondriasis with age may be associated with an increase in the number and range of unpleasant somatic sensations, both due to natural aging and due to increased depression. Similarly, an increase in characterological manifestations of hysteria, psychopathic deviate, paranoia and schizophrenia may be a manifestation of age-related increased sensitivity, affective lability, and decreased social activity. Gender differences are manifested by higher rates of depression in men, and hypochondriasis and psychasthenia in women. These differences may be associated with different psychological models of depression in men and women. Similarly, differences in higher rates of psychopathic deviate in women, which reflect stronger emotionality, less control over emotions, spontaneity of affective response in women, as well as higher rates of paranoia and schizophrenia in men, reflecting rigidity of affect, restraint, greater control over emotions inherent in men. At the same time, the individual variability of the personality profiles of patients with depressive disorders indicates the complex nature of personality changes and the need for further research in this area.

\section{Conclusions}

Depressive disorders are accompanied by pronounced pathocharacterological changes.

The basis of the personal characteristics of patients with depression is persistent depressive manifestations in combination with anxiety and somatic fixations.

In men, depressive manifestations are stronger than in women, and are accompanied by greater rigidity and alienation, and in women, persistent depressive manifestations are combined with higher anxiety, asthenia, emotional instability and spontaneity of emotions.

The general trend is an increase in depressive, hypochondriac, psychopathic, schizoid personality characteristics with age, while psychasthenic manifestations are maximum in the middle age group (30-44 years), and decrease in the older age group.

Prospects for further research are associated with the study of the pathophysiological and pathopsychological mechanisms of depression, taking into account age and gender factors, as well as with the development of differentiated therapeutic and preventive measures for depressive disorders.

\section{References}

Belov O., Pshuk N. (2020). Age and gender features of depressive and anxiety symptomatics of depressive disorders. Wiadomości Lekarskie, 73(7), 1476-1479.

Belov O.O., Pshuk N.G. (2019). Some trends of clinical and symptomatic pathomorphosis of depressive disorders taking into account the age factor. Wiadomości Lekarskie, 72(9), 1786-1790.

Cleare A., Pariante C.M., Young A.H. (2015). Evidence-based guidelines for treating depressive disorders with antidepressants: a revision of the 2008 British Association for Psychopharmacology guidelines. Journal of Psychopharmacology, 29(5), 459-525.

Fekadu N., Shibeshi W., Engidawork E. (2017). Major depressive disorder: pathophysiology and clinical management. Journal of Depression and Anxiety, 6(1), 255-257.

Klein D.N., Kotov R., Bufferd S.J. (2011). Personality and Depression: Explanatory Models and Review of the Evidence. Annu Rev Clin Psychol, 7, 269-295.

Kraus C., Kadriu B., Lanzenberger R., Zarate C.A., Kasper S. (2019). Prognosis and improved outcomes in major depression: a review. Translational Psychiatry, 9, 127.

Limandri B.J. (2018). Treatment-Resistant Depression: Identification and Treatment Strategies. 
Journal of Psychosocial Nursing and Mental Health Services, 56(9), 11-15.

Malhi G.S., Mann J.J. (2018). Depression. Lancet, 24(10161), 2299-2312.

Markova M., Rezunenko O., Kozhyna H. (2017). Contents and efficiency measures of psychoeducation in rehabilitation system of patients with bipolar affective disorder. Journal of Education, Health end Sport formerly Journal of Health Sciences, 7, 711-715.

McLachlan G. (2018). Treatment resistant depression: what are the options? BMJ, 363, k5354. Ogbo F.A., Mathsyaraja S., Koti R.K., Perz J. (2018) Page A. The burden of depressive disorders in South Asia, 1990-2016: findings from the global burden of disease study. BMC Psychiatry, 18, 333.

Pshuk N.G., Stukan L.V., Kaminska A.O. (2018). Introducing system of psychotherapeutic intervention for family caregivers of patients with endogenous mental disorders. Wiadomosci Lekarskie, 71(5), 980-985.

Wiles N., Taylor A., Turner N., Barnes M., Campbell J., Lewis G., Morrison J., Peters T.J., Thomas L., Turner K., Kessler D. (2018). Management of treatment-resistant depression in primary care: a mixed-methods study. British Journal of General Practice, 68(675), e673-e681.

Zaytsev V.P. (1981). Variant psihologicheskogo testa Mini-Mult [Variant of Psychological test Mini-Mult]. Psychological Journal. 3. 118-123.

Zuckerman H., Pan Z., Park C., Brietzke E., Musial N., Shariq A.S., Iacobucci M., Yim S.J., Lui L.M.W., Rong C., McIntyre R.S. (2018). Recognition and Treatment of Cognitive Dysfunction in Major Depressive Disorder. Frontiers in Psychiatry, 9, 655. 